
\title{
AdindaMasfer
}

Volume 1 Nomor 2, Januari 2022

DOI: https://doi.org/10.37726/adindamas.v1i2.322

\section{Pendampingan Menggapai Keberkahan Upah Kerja PLTA Ir. H. Djuanda di Kecamatan Jatiluhur Kabupaten Purwakarta}

\author{
Asep Dede Kurnia ${ }^{1}$, Ayi Nurbaeti², Ai Nuradilah ${ }^{3}$ \\ 1,2Sekolah Tinggi Iilmu Ekonomi Syariah (STIES) Indonesia Purwakarta \\ ${ }^{1}$ asepdedekurnia@gmail.com \\ 2ayinurbaeti@gmail.com \\ ${ }^{3}$ Mahasiswa Sekolah Tinggi Iilmu Ekonomi Syariah (STIES) Indonesia Purwakarta \\ 3ainuradilah009@gmail.com
}

\begin{abstract}
ABSTRAK
Uang banyak di bank tapi setiap hari cek-cok dengan istri. Anak-anak tidak mendatangkan kebahagiaan sekalipun jumlahnya banyak. Dengan teman dan jiran sekitar tidak ada yang baikan. Kendaraan selalu bermasalah. Ketaatan kepada Allah semakin hari semakin melemah. Pikiran hanya dunia dan dunia. Harta dan harta. Penglihatan selalu kepada yang lebih dalam masalah dunia. Tidak pernah puas, sekalipun mulutnya melantunkan alhamdulillah tiap menit. PKM ini bertujuan untuk melakukan pendampingan menggapai keberkahan upah kerja PLTA Ir. H. Djuanda Jatiluhur Kabupaten Purwakarta. Pelaksanaan pendampingan menggapai keberkahan upah kerja di PLTA Ir. H. Djuanda Jatiluhur Kabupaten Purwakarta dilakukan dengan 2 cara yaitu melalui kajian bersama dengan sistem ceramah antara pemateri dengan semua karyawan PLTA Jatiluhur Purwakarta. Selanjutnya melalui pengajian bersama sebagai salah satu ikhtiar menggapai keberkahan upah kerja dan perlindungan Allah SWT. Supaya terhindar dari upah dan rezeki yang tidak halal atau tidak berkah.
\end{abstract}

Kata kunci - Pemberdayaan, Keberkahan Upah Kerja, Menggapai Keberkahan.

\section{ABSTRACT}

There is a lot of money in the bank but every day the wife argues. Children do not bring happiness even if there are many. With friends and neighbors around there is 
nothing good. Vehicles are always in trouble. Obedience to Allah is getting weaker day by day. The mind is just the world and the world. Property and possessions. Always look to the deeper things of the world. Never satisfied, even though his mouth sings alhamdulillah every minute. This PKM aims to provide assistance to achieve the blessings of working wages for PLTA Ir. H. Djuanda Jatiluhur, Purwakarta Regency. Implementation of assistance to achieve the blessing of working wages at hydropower plant Ir. H. Djuanda Jatiluhur Purwakarta Regency carried out in 2 ways, namely through a joint study with a lecture system between the presenter and all employees of the Jatiluhur Purwakarta Hydroelectric Power Plant. Furthermore, through joint recitations as one of the efforts to achieve the blessings of work wages and the protection of Allah SWT. In order to avoid wages and sustenance that are not lawful or not blessed.

Keywords - Empowerment, Blessing of Work Wages, Reaching Blessing.

\section{PENDAHULUAN}

Upah secara ekonomi adalah harga yang harus dibayarkan kepada karyawan atas jasanya dalam produksi kekayaan, seperti faktor produksi lainnya dengan kata lain, upah adalah harga dari tenaga yang dibayar atas jasanya dan produksi ${ }^{1}$. Formulasi lain dalam mendefinisikan upah dapat dilihat dari Peraturan Pemerintah No. 8 Tahun 1981, mengenai perlindungan upah, yang dimaksud dengan upah adalah suatu penerimaan sebagai imbalan dari pengusaha kepada karyawan untuk suatu jasa yang telah dilakukan ${ }^{2}$. Dinyatakan dan dinilai dalam bentuk yang ditetapkan menurut suatu persetujuan atau peraturan perundangan dan dibayarkan atas dasar suatu perjanjian kerja antara pengusaha dan karyawan, termasuk tunjangan baik untuk buruh itu sendiri maupun keluarganya.

Dahulu seseorang datang kepada Imam Syafi' i mengadukan tentang kesempitan hidup yang ia alami. Dia memberi tahukan bahwa ia bekerja sebagai orang upahan dengan gaji 5 dirham. Dan gaji itu tidak mencukupinya ${ }^{3}$. Namun anehnya, Imam Syafi'i justru menyuruh dia untuk menemui orang yang mengupahnya supaya mengurangi gajinya menjadi 4 dirham. Orang itu pergi melaksanakan perintah Imam Syafi'i sekalipun ia tidak paham apa maksud dari perintah itu. Setelah berlalu beberapa lama orang itu datang lagi kepada Imam Syafi'i mengadukan tentang kehidupannya yang tidak ada kemajuan. Lalu Imam Syafi'i memerintahkannya untuk kembali menemui orang yang mengupahnya dan minta untuk mengurangi lagi

1 Fauzi Caniago, “Ketentuan Pembayaran Upah Dalam Islam," Textura 5, no. 1 (2018): 38-48.

2 Rosni Rosni, "Analisis Tingkat Kesejahteraan Masyarakat Nelayan Di Desa Dahari Selebar Kecamatan Talawi Kabupaten Batubara," JURNAL GEOGRAFI 9, no. 1 (April 2, 2017): 53, http://jurnal.unimed.ac.id/2012/index.php/geo/article/view/6038.

${ }^{3}$ Akh. Yunan Athoillah, "Mengapa Guru Madrasah Diniah Bertahan? (Studi Fenomenologi Komitmen Kerja Guru Di Lembaga Madrasah Diniyah Dengan Gaji Dibawah Upah Minimum)," Economicus : Jurnal Of Economics 1, no. 2 (2017): 44-66.

ADINDAMAS (Jurnal Pengabdian Kepada Masyarakat), Volume 1, Nomor 2, Januari 2022 http://journal.sties-purwakarta.ac.id/index.php/adindamas/ ISSN: 2798-2874 (Media Online) 2798-4702 (Media Cetak) 
gajinya menjadi 3 dirham. Orang itupun pergi melaksanakan anjuran Imam Syafi'i dengan perasaan sangat heran.

Setelah berlalu sekian hari orang itu kembali lagi menemui Imam Syafi'i dan berterima kasih atas nasehatnya. Ia menceritakan bahwa uang 3 dirham justru bisa menutupi seluruh kebutuhan hidupnya, bahkan hidupnya menjadi lapang ${ }^{4}$. Ia menanyakan apa rahasia di balik itu semua; Imam Syafi'i menjelaskan bahwa pekerjaan yang ia jalani itu tidak berhak mendapatkan upah lebih dari 3 dirham. Dan kelebihan 2 dirham itu telah mencabut keberkahan harta yang ia miliki ketika tercampur dengannya.

Lalu Imam Syafi'i membacakan sebuah sya'ir:

$$
\text { جمع الحرام على الحلال ليكثره \# دخل الحرام على الحلال فبعثره }
$$

Dia kumpulkan yang haram dengan yang halal supaya ia menjadi banyak.

Yang haram pun masuk ke dalam yang halal lalu ia merusaknya.

Bila gaji yang kita terima tidak seimbang dengan kerja, artinya kita sudah menerima harta yang bukan hak kita. Itu semua akan menjadi penghalang keberkahan harta yang ada, dan mengakibatkan hisab yang berat di akhirat kelak. Harta yang tidak berkah akan mendatangkan permasalahan hidup yang membuat kita susah, sekalipun bertaburkan benda-benda mewah dan serba lux.

Uang banyak di bank tapi setiap hari cek-cok dengan istri. Anak-anak tidak mendatangkan kebahagiaan sekalipun jumlahnya banyak. Dengan teman dan jiran sekitar tidak ada yang baikan. Kendaraan selalu bermasalah. Ketaatan kepada Allah semakin hari semakin melemah ${ }^{5}$. Pikiran hanya dunia dan dunia. Harta dan harta. Penglihatan selalu kepada yang lebih dalam masalah dunia. Tidak pernah puas, sekalipun mulutnya melantunkan alhamdulillah tiap menit.

Kening selalu berkerut. Satu persatu penyakitpun datang menghampiri. Akhirnya gaji yang besar habis untuk cek up ke dokter sana, periksa ke klinik sini. Tidak ada yang bisa di sisihkan untuk sedekah, infak dan amal-amal sosial demi tabungan masa depan di akhirat. Menjalin silaturrahim dengan sanak keluarga pun tidak $^{6}$. Semakin kelihatan mewah pelitnya juga semakin menjadi. Masa bodoh dengan segala kewajiban kepada Allah. Ada kesempatan untuk shalat ya syukur, tidak ada ya tidak masalah.

${ }^{4}$ Dedah Raudatul Jannah, “Analisis Pengelolaan Kas Masjid Agung Baing Yusuf Kabupaten Purwakarta (Ditinjau Dari Aspek Manajemen Dan Alokasinya)," EKSISBANK (Ekonomi Syariah dan Bisnis Perbankan) 3, no. 2 (2019): 136-147.

${ }^{5}$ Deti Komalasari, “Konsep Pemutusan Hubungan Kerja Dalam Ekonomi Islam” (IAIN Bengkulu, 2017).

${ }^{6}$ Syaiful Anwar and Rifda El- Fiah, "Studi Pengembangan Arah Kebijakan Penguatan Kegiatan Kemahasiswaan Universitas Islam Negeri Pada Bidang Pengembangan Bakat, Minat, Penalaran Dan Kewirausahaan Mahasiswa UIN Raden Intan Lampung," Al-Tadzkiyyah: Jurnal Pendidikan Islam 9, no. 1 (June 8, 2018): 1, http:/ / ejournal.radenintan.ac.id/index.php/tadzkiyyah/article/view/2602.

ADINDAMAS (Jurnal Pengabdian Kepada Masyarakat), Volume 1, Nomor 2, Januari 2022 http://journal.sties-purwakarta.ac.id/index.php/adindamas/ ISSN: 2798-2874 (Media Online) 2798-4702 (Media Cetak) 
Kegiatan PkM yang bertema pendampingan Menggapai Keberkahan Upak Kerja PLTA Ir. H. Djuanda di Kecamatan Jatiluhur diharapkan mampu meningkatkan etos kerja karayawan dan kondisi kondusif dalam bekerja di PLTA Ir. H. Djuanda di Kecamatan Jatiluhur.

\section{METODE}

\section{A. Tempat Dan Waktu}

Kegiatan pengabdian kepada masyarakat tentang Pendampingan Menggapai Keberkahan Upah Kerja PLTA Ir. H. Djuanda di Kecamatan Jatiluhur, tanggal 8 dan 15 Nopember 2019. Tim PkM mengidentifikasi masalah sesuai dengan rencana kegiatan.

\section{B. Ruang Lingkup Dan Objek Pengabdian}

Objek yang menjadi sasaran dari kegiatan pengabdian kepada masyarakat ini adalah seluruh karyawan yang bekerja di Pembangkit Listrik Tenaga Air (PLTA) Ir. H. Djuanda kecamatan Jatiluhur kabupaten Purwakarta.

\section{Pendekatan Atau Teknik Pengabdian}

Kegiatan pengabdian kepda masyarakat ini dilakukan dengan menggunakan pendekatan service learning, dengan melalui tiga tahapan, yakni tahapan persiapan, tahapan melayani, dan tahapan refleksi. Adapun dalam tahap melayani, sistem pendampingan yang diterapkan oleh Tim PKM menggunakan seminar atau halaqah setiap 2 minggu sekali.

\section{HASIL DAN PEMBAHASAN}

Dalam konsep Islam upah disebut dengan Ujrah, Ujrah sendiri dalam bahasa Arab mempunyai arti upah atau upah dalam sewa-menyewa, sehingga pembahasan mengenai ujrah ini termasuk dalam pembahasan ijarah yang mana ijarah sendiri mempunyai arti sendiri. Pengertian upah dalam kamus bahasa Indonesia adalah uang dan sebagainya yang dibayarkan sebagai pembalasan jasa atau sebagai pembayaran tenaga yang sudah dilakukan untuk mengerjakan sesuatu.

Upah adalah bagian rizki yang diberikan kepada manusia yang senantiasa mau berikhtiar mendapatkan nafkah, tentu sebagai seorang musim upah atau rizki yang kita dapatkan ingin bernilai berkah agar memberikan manfaat dunia dan akhirat. Untuk memperoleh keberkahan dalam hidup secara umum dan dalam usaha penghasilan secara khusus, terdapat dua syarat yang mesti dipenuhi.

Pertama : Iman Kepada Allah. Inilah syarat pertama dan terpenting agar rizki kita diberkahi Allah, yaitu dengan merealisasikan keimanan kepada Allah. Allah berfirman : 


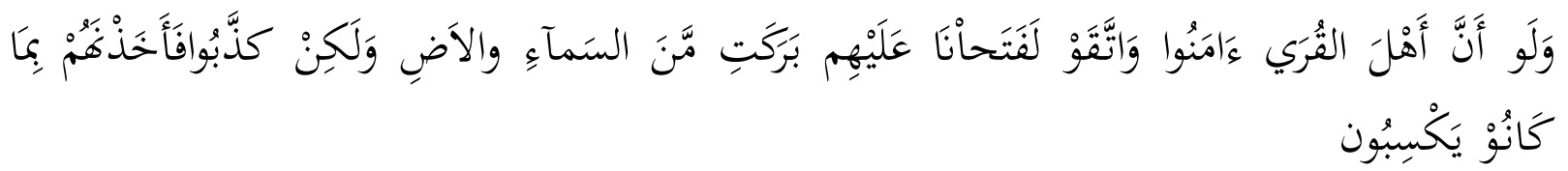

Seandainya penduduk-penduduk negeri bumi beriman dan bertaqwa, pastilah kami akan melimpahkan kepada mereka keberkahan dari langit dan bumi. Tetapi, mereka mendustakan ayat-ayat kami, maka kami siksa mereka disebabkan perbuatanya. (QS. AlA'raf : 96 ).

Diantara perwujudan iman kepada Allah yang berkaitan dengan penghasilan ,ialah senantiasa yakin dan menyadari bahwa rizki apapun yang kita peroleh merupakan karunia dan kemurahan Allah, bukan semata-mata jerihpayah atau kepandaian kita. Yang demikian itu, karena Allah telah menentukan kadar rizki setiap manusia semenjak ia masih berada dalam kandungan ibunya.

Kedua : Amal Shalih. Yang dimaksud dengan amal shalih, ialah menjalankan perintah dan menjauhi laranganya sesuai dengan syariat yang diajarkan oleh Rasulullah. Inilah hakikat ketakwaan yang menjadi syariat datangnya keberkahan, sebagaimana yang ditegaskan pada surat Al-A'raf ayat 96 diatas., Salah satu ayat yang mendukung syarat kedua ini adalah :

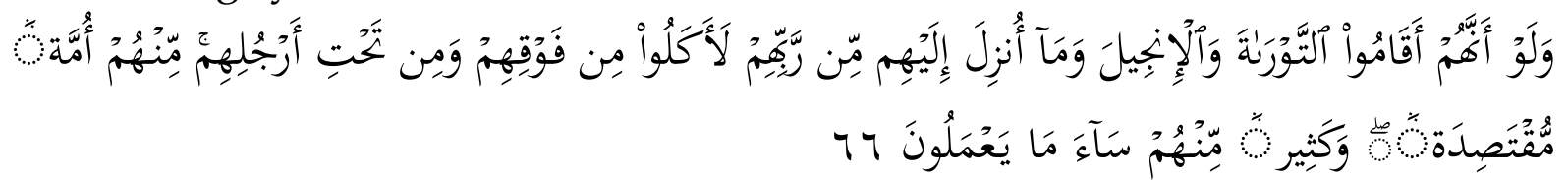

"Dan sekiranya mereka benar-benar menjalankan Taurat. Injil. Dan Al-Qur'an, yang diturunkan kepada mereka, niscaya mereka akan mendapatkan makanan dari atas mereka dan dari bawah kaki mereka. (QS. Al-Maidah : 66 )

Para Ulama tafsir menjelaskan, bahwa yang dimaksud dengan " mendapatkan makanan dari atas dan dari bawah kaki " ialah Allah akan melimpahkan kepada mereka rezeki yang sangat banyak dari langit dan dari bumi. Sehingga mereka akan mendapatkan kecukupan dan berbagai kebaikan, tanpa susah payah, leti,lesu dan tanpa adanya tantangan atau berbagai hal yang menggangu ketentraman kehidupan mereka. Beberapa amal soleh tersebut adalah :

1. Mensyukuri nikmat

2. Membayar zakat

3. Bekerja dengan hati qanaah

4. Bertaubat dari segala dosa

5. Menyambung silaturrahim

6. Mencari rizki yang halal.

Deskripsi Pelaksanaan Kegiatan Secara umum hasil kegiatan PkM merupakan upaya pemecahan masalah dan pemenuhan akan kebutuhan masyarakat serta 
tercapainya tujuan sebagai indikator keberhasilan. ${ }^{7}$ Hasil pelaksanaan program kerja PkM dapat dirasakan dari beberapa indikator yang muncul atau adanya perbedaan pada karyawan sebelum dan sesudah pelaksanaan pengabdian di masjid PLTA Ir. H. Djuanda di Kecamatan Jatiluhur. Adapun rencana-rencana kegiatan yang berhasil direalisasikan dalam kegiatan PkM di masjid PLTA Ir. H. Djuanda di Kecamatan Jatiluhur sebagai berikut :

1. Mengadakan kajian mengenai Menggapai Keberkahan Upah Kerja PLTA Ir. H. Djuanda di Kecamatan Jatiluhur Kabupaten Purwakarta

Kajian ini dimaksudkan untuk memberikan edukasi makna dan hakikat upah kerja dan cara menggapai keberkahan upah kerja yang didapatkan oleh setiap karyawan atau pegawai di PLTA Ir. H. Djuanda Jatiluhur Purwakarta.

Gambar 3.1

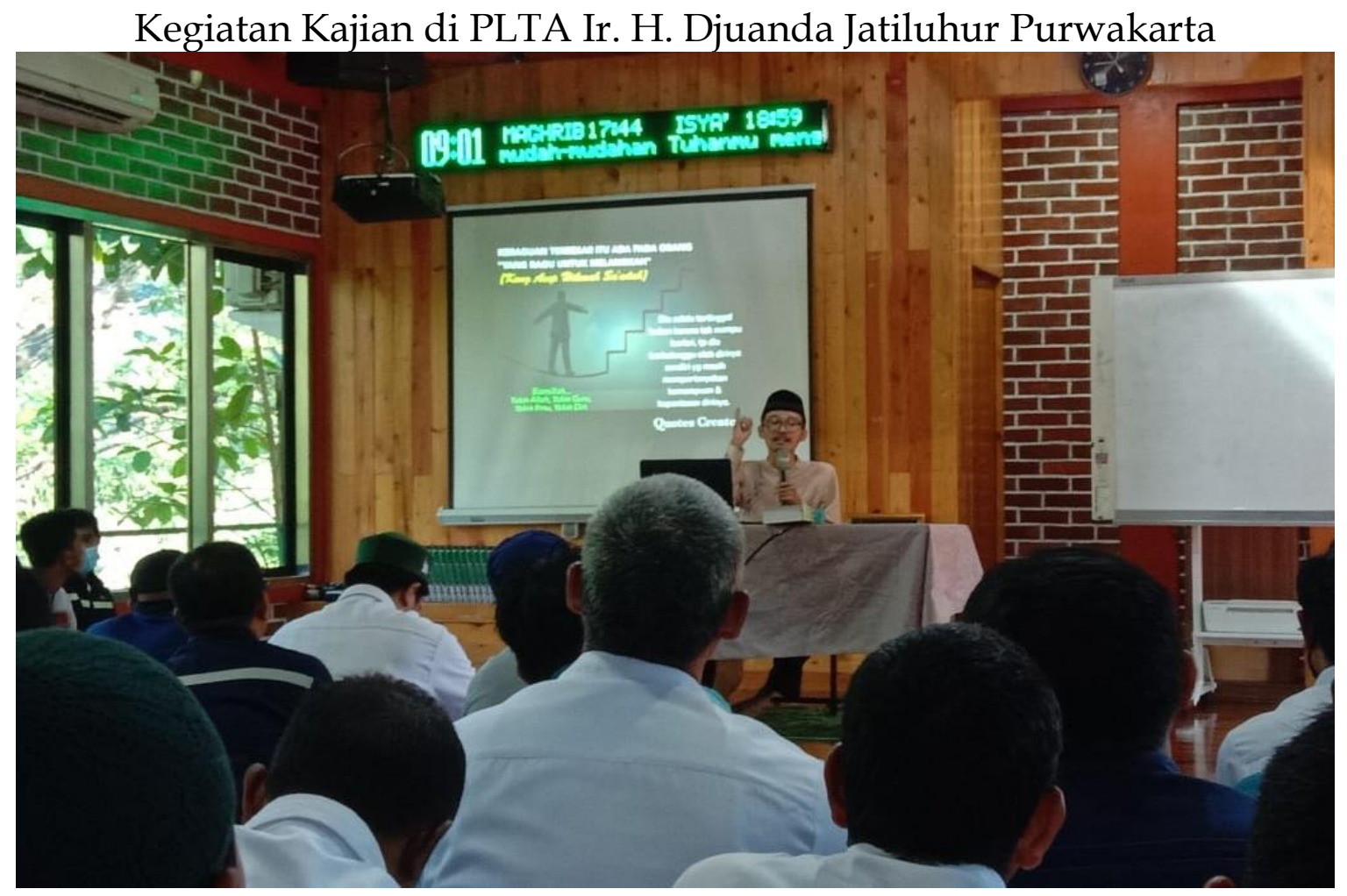

2. Proses pelaksanaan pengajian bersama karyawan Ir. H. Djuanda di Jatiluhur Purwakarta

Kegiatan pengajian bersama ini pun dimaksudkan sebagai salah satu ikhtiar untuk menggapai keberkahan upah kerja, karena keberkahan upah atau rezeki yang kita dapatkan selain prosesnya yang harus sesuai dengan rukun dan syarat atau sesuai dengan norma-norma agama islam, harus diimbangi juga dengan meminta pertolongan dan perlindungan kepada Allah SWT.

7 Jalaludin Jalaludin and Heru Komarujaman, “Talent Management Dalam Meningkatkan Kinerja Lembaga KSPPS BMT Mitra Sadaya Cabang Purwakarta," EKSISBANK: Ekonomi Syariah dan Bisnis Perbankan 2, no. 1 (June 25, 2018), http://journal.sties-purwakarta.ac.id/index.php/EKSISBANK/article/view/9.

ADINDAMAS (Jurnal Pengabdian Kepada Masyarakat), Volume 1, Nomor 2, Januari 2022 http://journal.sties-purwakarta.ac.id/index.php/adindamas/

ISSN: 2798-2874 (Media Online) 2798-4702 (Media Cetak) 
Supaya diberkahi dan dilindungi dari upah atau rezeki yang tidak halal. Kegiatan pengajian bersama ini merupakan kegiatan yang akan dirutingkan oleh pengurus DKM mesjid dan Karyawan di PLTA Ir. H. Djuanda Jatiluhur Purwakarta.

Gambar 3.2

Pelaksanaan Pengajian Bersama Karyawan Ir. H. Djuanda Di Jatiluhur Purwakarta

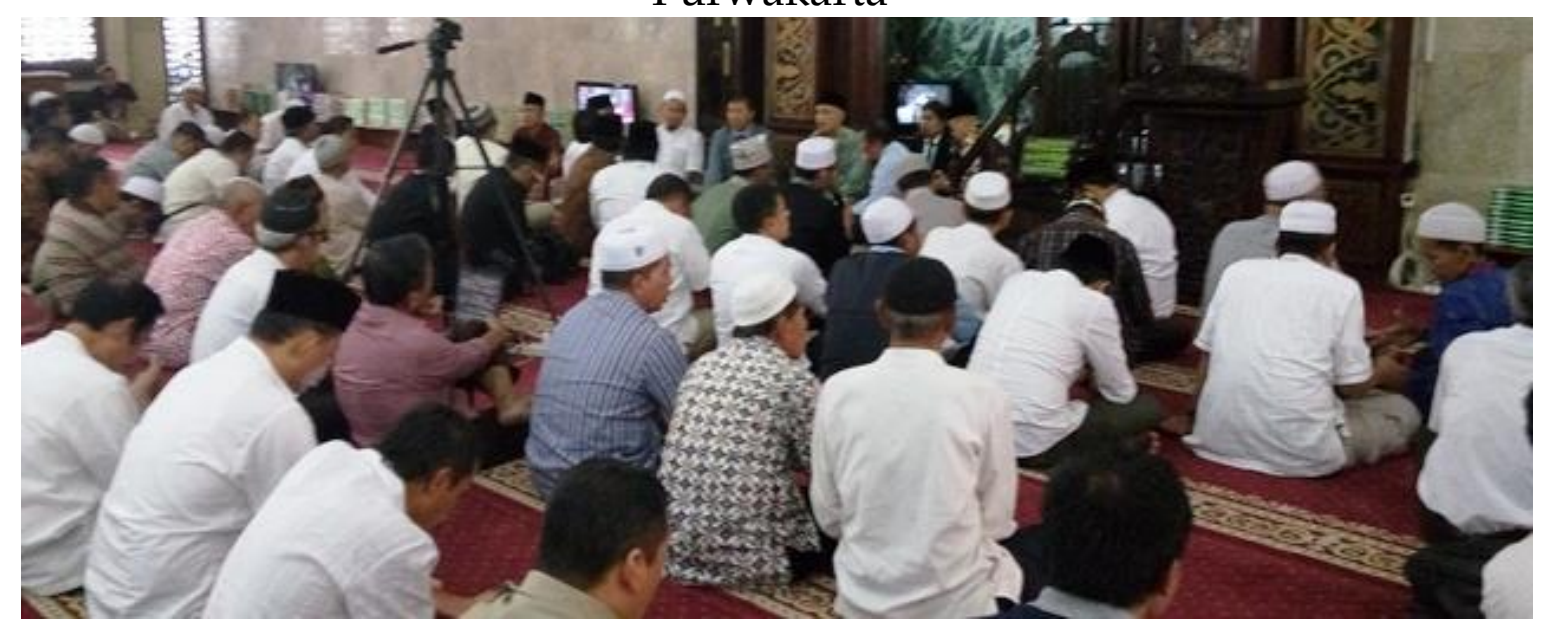

IV. KESIMPULAN

Pelaksanaan Pendampingan Menggapai Keberkahan Upah Kerja di PLTA Ir. H. Djuanda Jatiluhur Kabupaten Purwakarta dilakukan dengan 2 cara yaitu melalui kajian bersama dengan sistem ceramah antara pemateri dengan semua karyawan PLTA Jatiluhur Purwakarta. Selanjutnya melalui pengajian bersama sebagai salah satu ikhtiar menggapai keberkahan upah kerja dan perlindungan Allah SWT. Supaya terhindar dari upah dan rezeki yang tidak halal atau tidak berkah.

\section{DAFTAR PUSTAKA}

Anwar, Syaiful, and Rifda El- Fiah. “Studi Pengembangan Arah Kebijakan Penguatan Kegiatan Kemahasiswaan Universitas Islam Negeri Pada Bidang Pengembangan Bakat, Minat, Penalaran Dan Kewirausahaan Mahasiswa UIN Raden Intan Lampung." Al-Tadzkiyyah: Jurnal Pendidikan Islam 9, no. 1 (June 8, 2018): 1. http:/ / ejournal.radenintan.ac.id/index.php/tadzkiyyah/article/view/2602.

Athoillah, Akh. Yunan. “Mengapa Guru Madrasah Diniah Bertahan? (Studi Fenomenologi Komitmen Kerja Guru Di Lembaga Madrasah Diniyah Dengan Gaji Dibawah Upah Minimum)." Economicus : Jurnal Of Economics 1, no. 2 (2017): 44-66.

Caniago, Fauzi. “Ketentuan Pembayaran Upah Dalam Islam.” Textura 5, no. 1 (2018): 38-48.

Jalaludin, Jalaludin, and Heru Komarujaman. "Talent Management Dalam

ADINDAMAS (Jurnal Pengabdian Kepada Masyarakat), Volume 1, Nomor 2, Januari 2022 http://journal.sties-purwakarta.ac.id/index.php/adindamas/

ISSN: 2798-2874 (Media Online) 2798-4702 (Media Cetak) 
Meningkatkan Kinerja Lembaga KSPPS BMT Mitra Sadaya Cabang Purwakarta." EKSISBANK: Ekonomi Syariah dan Bisnis Perbankan 2, no. 1 (June 25, 2018). http://journal.sties-purwakarta.ac.id/index.php/EKSISBANK/article/view/9.

Jannah, Dedah Raudatul. "Analisis Pengelolaan Kas Masjid Agung Baing Yusuf Kabupaten Purwakarta (Ditinjau Dari Aspek Manajemen Dan Alokasinya)." EKSISBANK (Ekonomi Syariah dan Bisnis Perbankan) 3, no. 2 (2019): 136-147.

Komalasari, Deti. “Konsep Pemutusan Hubungan Kerja Dalam Ekonomi Islam." IAIN Bengkulu, 2017.

Rosni, Rosni. “Analisis Tingkat Kesejahteraan Masyarakat Nelayan Di Desa Dahari Selebar Kecamatan Talawi Kabupaten Batubara." JURNAL GEOGRAFI 9, no. 1 (April 2, 2017):

53. http:/ /jurnal.unimed.ac.id/2012/index.php/geo/article/view/6038. 